\title{
Bebida Alcoólica e Direção Automotiva: Relatos de Policiais Militares Sobre a "Lei Seca"
}

\author{
Andrea dos Santos Nascimento \\ Universidade Federal do Espírito Santo, ES, Brasil.
}

\author{
Paulo Rogério Meira Menandro \\ Universidade Federal do Espírito Santo, ES, Brasil.
}

\begin{abstract}
Resumo: Dirigir sob efeito de bebida alcoólica é comportamento de risco associado a expressivo volume de acidentes de trânsito. Em vários estados brasileiros foram adotadas ações de fiscalização e punição de motoristas flagrados em tal comportamento de risco. O objetivo do presente estudo foi conhecer o contexto atual de realizações e dificuldades um programa de fiscalização implantado em 2003, no estado do Espírito Santo, por meio de entrevistas com 25 policiais militares que atuam em tal programa. O material textual composto pela transcrição das entrevistas foi processado por meio do software Alceste, que organizou as respostas dos policiais em 6 classes de conteúdos: Naturalização e valorização do beber excessivo; Menosprezo do risco da associação entre bebida e direção; Realizações e dificuldades no contexto das ações de fiscalização; Realizações e dificuldades no contexto das ações educativas; Aspectos Legais e operacionais em torno da verificação da embriaguez; Aspectos legais e operacionais relativos à punição do condutor. Considera-se que as concepções de profissionais que participam de forma direta da intervenção relativa ao problema podem contribuir para a discussão e aprimoramento das modalidades de intervenção a serem continuadas.

Palavras-chave: Bebida alcoólica, Direção automotiva, Blitz, Educação para o trânsito, Avaliação psicológica de motorista, Programa madrugada viva.
\end{abstract}

\section{Alcoholic Beverage and Driving: Reports of Military Policy Officers on "Lei Seca"}

\begin{abstract}
To drive under the influence of alcohol is considered a risky behaviour and has been associated with a significant number of car accidents. Considering that, several Brazilian states have adopted control and punishing actions against drivers who are caught in such risky behaviour. The main objective of this study was to understand the current context of achievements and difficulties of a monitoring program implemented in 2003 in the state of Espirito Santo. To this end, twenty-five military officers who work in this program were interviewed. The resulting data was transcribed and processed through the software Alceste, which organized the responses of police officers in 6 classes of contents: naturalization and appreciation of excessive drinking; underestimation of the risk of association between drinking and driving; achievements and difficulties in the context of enforcement actions; achievements and difficulties in the context of educational activities; legal and operational aspects around the verification of drunkenness; and legal and operational aspects regarding punishment of the driver. It is considered that the views of professionals who participate directly on the issue of intervention can contribute to the discussion and improvement of methods of future possible intervention.

Keywords: Alcoholic beverage, Automotive steering, Blitz, Traffic education, Psychological evaluation of the driver, Program morning alive.
\end{abstract}




\title{
Bebida alcohólica y conducción automovilística. Relato de policías militares sobre la "ley seca".
}

\begin{abstract}
Resumen: Conducir bajo los efectos de bebidas alcohólicas es considerado un comportamiento de riesgo asociado a un gran número de accidentes de tránsito. En varios estados brasileros fueron adoptadas acciones de fiscalización y punición de conductores sorprendidos conduciendo bajo los efectos del alcohol. El objetivo del presente estudio fue conocer el contexto actual y las dificultades del programa de fiscalización implantado en 2013, en el estado de Espíritu Santo, por medio de entrevistas con veinticinco policías militares que actúan en tal programa. Los datos obtenidos, compuestos por transcripciones de las entrevistas, fueron procesados por medio del software Alceste, que organizó las respuestas de los policías en 6 clases de contenidos: naturalización y valorización del consumo excesivo de alcohol; subestimación del riesgo de la relación entre bebida y conducción; realización y dificultad en el contexto de las acciones impositivas; realización y dificultad en el contexto de las acciones educativas; aspectos legales y operacionales en torno a la verificación del estado de embriaguez; y aspectos legales y operacionales relativos a la punición del conductor. Se considera que las concepciones de los profesionales que participan de forma directa en la intervención relativa al problema pueden contribuir para la discusión y actualización de las modalidades de intervención que seguirán a futuro.

Palabras clave: Bebida alcohólica, Conducción automotriz, Blitz, Educación para el transito, Evaluación psicológica del conductor, Programa madrugada viva.
\end{abstract}

Na literatura, é unânime a compreensão de que as cidades estão crescendo e se alterando em ritmo cada vez mais acelerado, o que já se observava desde a revolução industrial, mas que ganhou novas características ao longo do século XX com as transformações nos modos de produção que levaram à grande hegemonia da vida urbana, caracterizando o que deve ser considerado, como afirmou Damiani (2006), "uma urbanização descompassada". Essa unanimidade permanece válida quando são observadas as discussões de diferentes autores a despeito da diversidade de denominações atribuídas à cidade expandida ${ }^{1}$.

Moura, Castello Branco e Firkowski (2005) defendem que não há como discutir o tema das cidades sem considerar que nesse espaço existem pessoas, conflitos, interesses divergentes e convergentes, disputa de poder e, como necessidade intrínseca e inevitável, movimento e mobilidade. Mobilidade, para as autoras, é movimento que deve ser pensado em relação direta com o transporte e com a dimensão de uma cidade.
O veículo motorizado (motocicletas, transporte coletivo, automóvel particular) nesse contexto, é um dos responsáveis pelos movimentos que ocorrem permanentemente na "vida" de uma cidade e há certo destaque para o transporte individual nesse modo de circulação (Barczak, \& Duarte, 2012; Bonduki, 2011; Rolnik, \& Klintowitz, 2011). Para Dupuy (1995) e Ludd (2005), o automóvel motorizado traz consigo uma maneira peculiar de movimento, de deslocamentos humanos, de negociação de mercadorias, de ecologia, de relações humanas e sociais, de hierarquias, capaz de transformar a forma de (con)viver em uma cidade. Nesse sistema, os autores concordam que o automóvel particular demonstra de forma inequívoca sua superioridade, agilidade e conforto, não experimentados nos transportes públicos coletivos na maioria das cidades, principalmente nos países subdesenvolvidos.

Dizer que a maioria das atividades humanas se dá no espaço público não parece descabido. Deslocar-se de um lugar a outro é algo natural e cotidianamente necessário ao ser humano. O que varia são as motivações e

1. Essas denominações são um esforço teórico para denominar as “cidades gigantes” tal como são chamadas as metrópoles ou megametrópoles. Essas terminologias expressam a expansão desordenada que têm trazido mais problemas e desafios para as políticas territoriais e de planejamento urbano. 
as formas de deslocamento (ANTP, 1997; Vasconcellos, 2005). É importante ressaltar, a partir daí, que o uso do espaço público não é compartilhado de forma democrática ou equitativa. Este ponto interessa à presente investigação porque os automóveis se tornaram elementos indispensáveis para a consolidação do entendimento de que a algumas pessoas era facultado o uso das vias públicas de forma privilegiada ou preferencial - as pessoas que podiam se deslocar de carro. O crescimento das cidades e o tipo de ocupação de seus espaços que as diferenças econômicas entre os que nela vivem geram configuração na qual, muitas vezes, a habitação está afastada dos locais de trabalho por distâncias inviáveis de serem percorridas a pé no dia a dia. A alternativa para a maior parte dos moradores envolve o uso de transportes coletivos, alternativa essa que, na maior parte do país, se resume a ônibus ou trens de superfície, uma vez que algumas alternativas bem-sucedidas em outros locais não foram facilitadas pelos planejadores e com isso tiveram pouca adesão (como o uso de bicicletas) ou só começaram a se tornar realidade ao final da década de 1970, em algumas poucas metrópoles brasileiras (como é o caso do metrô). A possibilidade diferenciada que se apresenta aos que tenham condições financeiras privilegiadas e que foi sempre muita valorizada pela autonomia que dela resulta, associada ao prestígio social concedido aos que dela podem usufruir, é o uso de automóveis privados.

Até quase ao final da década de 1950 não existiam indústrias de automóvel no Brasil, embora algumas "fábricas" estrangeiras já estivessem aqui instaladas, mas com a responsabilidade da montagem parcial e manutenção de veículos produzidos fora do país. Os automóveis que aqui circulavam eram todos importados e seu custo (mesmo no caso de automóveis simples) os tornavam inacessíveis à expressiva maioria da população. No início dos anos 1940, coincidindo com a Segunda Grande Guerra, houve contenção na importação de veículos e autopeças. Em meados da década de 1940, nogoverno Dutra, terminada a Segunda Guerra Mundial, a importação de carros acelerou-se, mas o custo para o país era demasiadamente elevado e se começou a planejar a possibilidade de produzir automóveis em território nacional, atraindo alguns dos fabricantes sediados na Europa ou nos Estados Unidos. O planejamento (ou sua falta) de modernização das grandes cidades em resposta ao crescimento populacional urbano foi, em grande parte, criação de condições para que mais automóveis pudessem circular com a rapidez e com os privilégios que seus donos "mereceriam" devido ao seu status diferenciado (ampliação de ruas e avenidas, pontes e viadutos, túneis, asfaltamento para possibilitar maior velocidade, estacionamentos, aterros, entre outras medidas).

De fato, a sociedade capitalista enaltece quem é possuidor de um automóvel e confere a ambos, objeto e seu dono, o valor semelhante ao que, em tempos passados, foi associado à nobreza. O ser humano adquire o valor simbólico do objeto (Ludd, 2005; Lorentz, 2008) e agrega privilégios ao seu deslocamento, tanto em termos de prestígio autopercebido, como no imaginário coletivo, possibilidades essas cujas bases estão na existência concreta de privilégios e vantagens (Jato, 2007; Lorentz, 2008; Ludd, 2005).

Retornando ao tema do deslocamento urbano, fica evidente, como foi argumentado, que envolve negociação cada vez mais complexa e conflituosa pelo espaço e na qual os interessados não atuam em condições igualitárias. O modus operandi que pressupõe uma base ideológica e política, a partir de como os sujeitos de uma sociedade se percebem nela, seus papéis e posição social (Vasconcellos, 1998). O motorista no Brasil está no ápice desta relação. A ele está dado o direito simbólico de circular livremente e com mais prioridade que os demais participantes da via pública. Por outro lado, os demais componentes acabam se colocando no lugar de cidadãos de "segunda classe" (DaMatta, Vasconcellos, \& Pandolfi, 2010; Vasconcellos, 1998).

DaMatta et al. (2010) ofereceram uma analogia interessante e curiosa fazendo referência ao comportamento da corte portuguesa no Brasil:

O protocolo real obrigava os passantes a parar, apear os cavalos ou sair das carruagens para reverenciar a corte quanto esta transitava pelas ruas, numa prova de respeito pela distância social e pela sacralidade que revestia figuras que eram a representação concreta de autoridade e de poder real. A confusão entre a rua aberta que pertence a todos (ainda que torta e mal pavimentada, como recorrentemente observam os viajantes europeus que visitavam o Brasil), e uma outra, fechada e aristocrática, feita para poucos, ocorria quando por ela passavam membros da realeza (DaMatta et al., 2010, p. 36).

Assim, permanece a ideia simbólica e valorativa, desde 1800 por assim dizer, de que o pedestre, 
o ciclista, ou outros que equivalente àquele sujeito considerado de "baixo escalão" (que não tem seu veículo automotor) que "apeie de seu cavalo", pois a nobreza (o veículo e seu proprietário) está passando.

Vasconcellos (2005) registra que as pessoas em idade produtiva, escolares ou trabalhadores, são as que mais saem de suas residências. A natureza e a quantidade de deslocamentos estão relacionadas à renda da pessoa ou da família. O autor argumenta que quanto menor a possibilidade de pagar pelos deslocamentos menos deslocamentos a pessoa/família irá fazer, restringindo-se, certamente, ao uso do transporte coletivo. Vasconcellos (2005) faz ainda uma observação provocativa quando, ao comparar os modos de locomoção (automóvel particular, ônibus, táxi, bicicleta, a pé), afirma que o automóvel particular, mesmo sendo mais poluente e transportando menor número de pessoas, se impõe apenas pela comodidade, pois o status quo do proprietário (ou da família) é argumento que "justifica” o aumento de liberdade e de mobilidade de tais usuários que, assim, não ficariam presos aos itinerários e horários dos ônibus, nem à convivência social forçada com outros cidadãos comuns, como acontece nos transportes públicos. O aumento do uso de veículo individual e, como uma de suas consequências, a dificuldade de fluidez na mobilidade são patentes. De 30 mil veículos automotores produzidos em 1957, chegou-se a 3 milhões em 2011 (Anfavea, 2012).

A discussão da mobilidade urbana acompanha os estudos sobre os acidentes de trânsito. A partir de uma revisão de estudos sobre fatores humanos a serem considerados como causas ou como item do conjunto de elementos causais de acidentes rodoviários, Petridou e Moustaki (2000) propuseram um modelo de classificação desses fatores que, segundo eles, são responsáveis por mais da metade dos acidentes, além de contribuir para a ocorrência dos outros restantes. Esses autores lembram que os acidentes de trânsito respondem por volume substancial de casos de morbidade e mortalidade humana e são responsáveis por mais anos de vidas perdidas do que muitas doenças.

No modelo proposto (Petridou, \& Moustaki, 2000), diferenciam-se os fatores comportamentais em quatro vertentes. A primeira vertente diz respeito aos fatores que reduzem a capacidade de dirigir em um horizonte de longo-prazo: inexperiência, envelhecimento, doença e incapacidade, abuso de drogas, alcoolismo. A segunda vertente refere-se igualmente aos fatores que reduzem a capacidade de dirigir em curto prazo: sonolência, efeitos de curto prazo de drogas, ingestão de quantidade excessiva de comida, estresse psicológico agudo, distração ou desorientação temporária, intoxicação alcoólica aguda. A terceira vertente engloba fatores que promovem comportamento de assumir risco com impacto em longo prazo: atitude "de macho", velocidade excessiva habitual, desconsideração habitual das regras de tráfego, comportamento inadequado na direção, não uso de cinto de segurança ou capacete, propensão para acidente, superestimação de habilidades. A quarta vertente também abrange fatores que promovem comportamento de assumir risco, mas com impacto de curto prazo: drogas psicotrópicas, criminalidade relacionada a veículos, comportamento suicida, atos compulsivos, moderada ingesta alcoólica. Fica evidente em tal modelo (ver destaques em itálicos) a presença da ingestão de bebida alcoólica como fator que reduz a capacidade de dirigir, em curto e em longo prazo. A bebida alcoólica também está presente entre os fatores que promovem comportamento de assumir riscos. É possível indicar, também, vários fatores com os quais o consumo de bebida alcoólica pode interagir, entre eles sonolência, distração, desconsideração de regras, comportamento inadequado, e superestimação de habilidade.

Brismar eBergman (1998) consideram ser a ingestão de bebida alcoólica fator de risco tanto para quem está em atividade de condução de veículo automotor como para pedestres em trânsito, tendo constatado que jovens do sexo masculino estão diferencialmente representados (com alto percentual) nos acidentes de trânsito em que houve envolvimento de bebida alcoólica. Oliveira, Yonamine, Andreucceti, Ponce e Leyton (2012) reuniram dados que evidenciam que bebida alcoólica e substâncias psicoativas são colaboradores, diretos ou indiretos, para a ocorrência dos acidentes de trânsito no Brasil com motoristas de caminhão.

Em estudo da Secretaria Nacional sobre Drogas no Brasil, organizado por Pechansky, Duarte e De Boni (2010), 9,6\% dos entrevistados afirmaram ter ingerido bebida alcoólica no dia da entrevista. Os entrevistados relataram que o uso de álcool e outras drogas serve como suporte para as pressões às quais caminhoneiros são expostos, tais como longas jornadas de trabalho, assaltos na estrada, poucas horas de sono, trabalho por turno, prazos curtos de entrega e recebimento de mercadoria e ausência da família. Os autores 
registram que o uso de bebida alcoólica e de outras drogas em autoestradas aumentam as chances e a gravidade das consequências de acidentes, além de onerar o sistema de saúde pública, o judiciário e o sistema de segurança pública.

Leyton, Greve, Carvalho e Muñoz (2005) partiram da suposição de que quanto maior a quantidade de álcool no sangue maior a morbimortalidade nos acidentes de trânsito. Analisaram 2.360 requisições de verificação de alcoolemia do Instituto Médico Legal do Estado de São Paulo para vítimas fatais de acidentes de trânsito, nas categorias colisões e atropelamentos, ocorridos de janeiro a dezembro de 1999. Para fins desse estudo foram consideradas como positivas as amostras de sangue que tiveram concentração igual ou superior a $0,1 \mathrm{~g} / \mathrm{l}$ sangue. A pesquisa constatou que o resultado do exame de álcool etílico foi positivo no sangue de quase da metade das vítimas de acidentes de trânsito (47\%). Vítimas do sexo masculino, com idade entre 25 a 40 anos, constituem o segmento mais presente no conjunto dos casos.

Moura, Malta, Morais-Neto, Penna e Temporão (2009), partindo da mesma suposição mencionada no parágrafo anterior e defendendo que os acidentes de trânsito são um problema de saúde pública, buscaram verificar o volume de adultos que dirigiam alcoolizados nas capitais dos estados brasileiros e no Distrito Federal. Para tanto, dados autorrelatados, levantados por meio do sistema de Vigilância de Fatores de Risco e Proteção para Doenças Crônicas por Inquérito Telefônico (Vigitel), foram analisados. Em 2007 foram entrevistadas 54.251 pessoas, em 2008 foram $54.353 \mathrm{e}$ em parte de 2009 foram 22.009 entrevistados. Uma das questões formuladas abordava a vinculação consumo de bebida alcoólica e direção automotiva. A admissão de ter dirigido após consumo de bebida alcoólica pelo menos uma vez no último mês foi feita por $4,0 \%$ dos homens e $0,3 \%$ das mulheres em 2007 , por $3,0 \%$ dos homens e $0,3 \%$ das mulheres em 2008 (os dados de 2009 não são apresentados separadamente para homens e mulheres). Os menores percentuais de entrevistados (homens e mulheres agrupados) que admitiram ter bebido e dirigido foi constatado no primeiro $(1,3 \%)$ e no segundo mês $(0,9 \%)$ após a publicação da Lei Seca (Lei no 11.705), que ocorreu em julho de 2008.

Campos, Salgado, Rocha, Duailibi e Laranjeira (2012) realizaram estudo utilizando metodologia designada como postos de fiscalização de sobrie- dade, na qual motoristas em trânsito por vias movimentadas são parados e convidados a participar de estudo respondendo a questionário e fazendo teste com etilômetro. A localização dos postos foi decidida em conjunto com autoridades de trânsito e a abordagem dos motoristas foi feita por equipes de policiais militares. Os participantes eram informados de que seus dados (do questionário e do etilômetro) não seriam compartilhados com a polícia. O estudo foi feito em dez cidades de Minas Gerais, com coleta de dados nas madrugadas das sextas-feiras e sábados. De 1.951 motoristas abordados, 1.799 responderam o questionário e entre esses, 1.209 aceitaram submeter-se ao etilômetro. No grupo de participantes, predominaram homens $(87,4 \%)$, com idade até 30 anos $(59,3 \%)$ e escolaridade de nível superior (46,6\%). Já se envolveram em acidente de trânsito $35,3 \%$ dos motoristas abordados, e ingerem bebida alcoólica diariamente ou a cada dois dias $42,7 \%$ deles. Impressiona o fato de 475 pessoas $(26,5 \%$ do total e $40,1 \%$ dos que não são abstêmios) admitirem ter bebido naquele próprio dia da pesquisa. Tal dado está em acordo com a constatação de que $20 \%$ dos condutores apresentavam concentração de álcool no ar expirado acima do limite legal.

Passando dos relatos de investigações para aspectos históricos da legislação pertinente ao tema, constata-se, de início, que é muito recente, no Brasil, a normatização do uso de bebida alcoólica e outras drogas em situação de direção de veículos automotores, podendo ser ressaltados dois momentos. No primeiro momento, a Lei $\mathrm{n}^{\circ} 11.705$, de 19 de junho de 2008, popularizada como Lei Seca, alterou item do Código de Trânsito assinalando que caracteriza infração gravíssima "dirigir sob a influência de álcool ou de qualquer substância psicoativa que determine dependência" (Brasil, 2008, p. 36). A penalidade é de multa (à época, $\mathrm{R} \$ 957,69$ ), acrescida da suspensão do direito de dirigir por doze meses. A medida administrativa adotada é a retenção do veículo até apresentação de condutor habilitado, bem como o recolhimento do documento de habilitação. No mesmo dispositivo legal está regulamentado o procedimento de apuração da embriaguez:

Art. 277. Todo condutor de veículo automotor, envolvido em acidente de trânsito ou que for alvo de fiscalização de trânsito, sob suspeita de dirigir sob influência de álcool, 
será submetido a testes de alcoolemia, exames clínicos, perícia ou outro exame que, por meios técnicos ou científicos, em aparelhos homologados pelo CONTRAN, permitam certificar seu estado (Redação dada pela Lei $\mathrm{n}^{\mathrm{o}}$ 11.275, de 07/02/2006) (Brasil, 2008, p. 49).

Em outro ponto do Código de Trânsito Brasileiro, no Capítulo XIX, que trata dos Crimes de Trânsito, está disposto que a esses crimes se aplicam as normas gerais do Código Penal e do Código de Processo Penal. Entretanto, se o motorista estiver sob influência de álcool ou qualquer outra substância psicoativa que determine dependência, a ele não poderá ser aplicada, havendo crime de trânsito com feridos, a responsabilidade de lesão corporal culposa (que ocorreu sem que tenha havido intenção de produzi-la). A ele, é reservada na seção II do mesmo capítulo no artigo 306 a pena de detenção de seis meses a três anos, multa e suspensão ou proibição de se obter a permissão ou a habilitação para dirigir veículo automotor. É de conhecimento geral e causa perplexidade o fato de até pouco tempo atrás não existir no Brasil qualquer caso em que alguma pessoa tenha sido condenada e tenha cumprido pena de privação de liberdade por crime de trânsito que envolva a ingestão de bebida alcoólica. Tal situação vem mudando, ainda que de forma bastante lenta, como informa a Associação Brasileira de Educação de Trânsito, ao divulgar recentemente que já são conhecidos nove casos de condenações, com condenados cumprindo pena ou, em alguns casos, recorrendo em liberdade (Abetran, 2014).

Em um segundo momento a história toma outro rumo. A Lei $\mathrm{n}^{0} 11.705$, de 2008, sofreu profundas alterações, de acordo com texto da Lei ${ }^{\circ} 12.760$, de 20 de dezembro de 2012 (Salgado, Campos, Duailib, \& Laranjeira, 2012). A Nova Lei Seca - epíteto propagado pelos meios de comunicação - permitiu às autoridades de trânsito se valerem de outros meios de prova especificados como admissíveis, além do etilômetro (bafômetro), para a constatação do crime de embriaguez ao volante. $\mathrm{O}$ agente de trânsito poderá utilizar depoimentos de terceiros, vídeos, fotos e outras possibilidades que evidenciem que o condutor ingeriu bebida alcoólica antes de dirigir. O novo dispositivo legal dobrou o valor da multa e a quadruplicou em caso de reincidência, podendo atingir $\mathrm{R} \$ 3.830,80$. A medida administrativa permanece inalterada, mas, se constatada embriaguez superior a $0,6 \mathrm{~g} / \mathrm{l}$ de álcool no sangue (crime de trânsito), haverá detenção de seis meses a três anos.

Em janeiro de 2013 ocorreu nova alteração. O Conselho Nacional de Trânsito publicou a Resolução no 432 , com os procedimentos cabíveis para agentes de trânsito verificarem o consumo de álcool ou outra substância psicoativa. A medida administrativa não muda, assim como o uso do etilômetro, mas outras modalidades de provas, além do testemunho do agente de trânsito, são incorporadas como válidas, entre elas imagem fotográfica, vídeo ou outras provas admitidas no âmbito do direito. A Resolução no 432 incorpora uma tabela de valores referenciais para etilômetro e uma listagem de sinais de alteração da capacidade psicomotora. É importante assinalar que recusa a submeter-se ao exame do etilômetro não caracteriza crime, mas a quem o fizer serão aplicadas medidas administrativas e penalidades associadas.

Bem antes desses momentos foi colocado em prática, no estado do Espírito Santo, o programa que representa o contexto ao qual se referem os dados da presente pesquisa. Trata-se do Programa Madrugada Viva criado em 2003, frente à constatação, pelo Detran-ES, de aumento de acidentes de trânsito causados por abuso de bebidas alcoólicas antes de dirigir. Em tal programa, as abordagens dos motoristas envolviam duas frentes: a abordagem educativa, com uso de panfletos informativos e cartilhas sobre direção segura (cinto de segurança, velocidade e abuso de bebida alcoólica); e a abordagem punitiva, na qual o motorista flagrado embriagado (com uso do etilômetro) por policiais do Batalhão de Trânsito é autuado, têm o veículo retido e a carteira de habilitação apreendida. O Programa Madrugada Viva foi o único programa na esfera governamental, em todo o Brasil, iniciado antes da promulgação da Lei $n^{\circ} 11.705$, de 2009, conhecida como Lei da Tolerância Zero ou Lei Seca (Nascimento, 2008).

O procedimento, longe de ser complexo, consistia em abordar os motoristas de diferentes faixas etárias, mas principalmente os jovens. O motorista abordado é convidado por um policial de trânsito a fazer uso do etilômetro. Havendo constatação de ter havido consumo de bebida alcoólica, o motorista é encaminhado à Delegacia de Delitos de Trânsito para os procedimentos cabíveis. Sabedores de que não estão legalmente obrigados a submeterem-se ao etilômetro, alguns motoristas optam por não fazê-lo. Nesse caso, 
o agente de trânsito pode lavrar um Exame Etílico (Exame de Alcoolemia, conforme Resolução do Conselho Nacional de Trânsito) ou encaminhar o motorista à Delegacia, para que seja lavrado exame testemunhal no qual ele é avaliado por sua condição física e emocional (equilíbrio, alterações na fala, hálito, olhos vermelhos, entre outros indicadores) pelos policiais presentes e testemunhas.

Os policiais militares do Batalhão de Trânsito que trabalham no Programa Madrugada Viva estão no foco do presente estudo. O objetivo é conhecer o contexto atual no qual se desenvolve o programa, na visão dos policiais militares que nele atuam. O que se buscou foi investigar as reflexões desses policiais sobre o programa, com ênfase nos aspectos que consideram bem-sucedidos, nas dificuldades que apontam para a realização mais eficiente de seu trabalho, na natureza das interações com os motoristas abordados, na repercussão do programa na sociedade, e nas sugestões que têm a oferecer juntamente com as justificativas que as embasam. Considerou-se que uma investigação apoiada no conhecimento desses profissionais pode ser contribuição importante para aprimorar a qualidade do programa.

\section{Método}

Foram realizadas entrevistas com 25 policiais militares do Batalhão de Trânsito. Os participantes foram convidados a conceder a entrevista e foram informados de que o anonimato seria assegurado, tendo manifestado sua concordância assinando um termo com tal conteúdo. Após transcritas, as entrevistas foram enviadas a quem a concedeu para que averiguasse as informações prestadas e fizesse eventuais modificações.

Considerando os objetivos da investigação, optou-se por entrevistas individuais semiestruturadas, em busca de conteúdos que revelassem regularidades, associações e contradições, de forma a contribuir para a adequada interpretação das concepções a respeito dos temas que interessam à investigação. A entrevista individual foi adotada, de acordo com proposições de Gaskell, \& Bauer (2002) e de Creswell (2007), pela riqueza de detalhes que proporciona, por propiciar a condução do processo de maneira a deixar o participante o mais confortável possível, reduzindo a chance de ambiguidade em relação às perguntas realizadas, e também por proporcionar a observação direta de eventuais reações informativas em relação aos propósitos da pesquisa.

Antes de iniciar a apresentação dos resultados, são apresentadas informações adicionais sobre os participantes. Todos os 25 policiais atuam nas ações do programa, na região metropolitana da Grande Vitória. São 15 homens e 10 mulheres. Suas idades variam entre 22 e 49 anos, situando-se onze participantes na faixa etária que se estende até 30 anos; seis na faixa entre 31 e 40 anos e oito com idades acima de 41 anos. Estão na corporação há mais de 20 anos oito policiais, entre 10 e 20 anos seis, e 11 atuam há menos de 10 anos. Apenas um participante participa de blitz desde o início do programa, em 2003. Quatro participantes iniciaram sua atuação em blitz em 2004 e dois começaram a participar quando foi lançada a fase punitiva do programa, em 2005. Os demais participantes passaram a atuar após 2007 (treze deles) ou não souberam precisar a data solicitada. Em relação à patente militar dos participantes, são 14 soldados; dois cabos; dois sargentos; um capitão; três subtenentes e três tenentes, ou seja, 18 (72\%) não oficiais e sete $(28 \%)$ oficiais.

\section{Resultados e discussão}

O texto completo resultante da transcrição das entrevistas concedidas foi submetido ao procedimento de organização e análise proporcionado pelo software Alceste (Analyse Lexicale par Contexte d'um Ensemble de Segments Texte), desenvolvido por Max Reinert (1990) para análise de dados textuais. Seu objetivo, ao processar as respostas dadas pelos participantes às perguntas abertas, é proporcionar uma categorização estatística do corpus textual, gerando categorias de palavras que aparecem associadas entre si, indicando que cada uma dessas categorias encerra um conteúdo diferenciado. Para chegar a tal resultado, o software identifica coocorrência de palavras em segmentos de texto e agrupa em classes conjuntos de palavras que coocorrem diferencialmente, ou seja, palavras que estão associadas entre si de forma privilegiada, para o que considera frequência e percentual de ocorrências na classe. Para o cálculo da associação das palavras à classe é utilizado o $x^{2}$. O software propicia ao pesquisador localizar cada segmento de texto em que a palavra foi empregada, o que muitas vezes é necessário para eliminar dúvidas.

Cada conjunto de material textual pode ser identificado em termos de variáveis a ele associadas 
e que sejam relevantes para o objetivo da investigação - em se tratando de textos que são transcrições de entrevistas, as variáveis potencialmente relevantes são certas características dos entrevistados. No caso do presente estudo foram consideradas as variáveis sexo, tempo na corporação, e patente militar (oficial ou não oficial).

Como diferentes pessoas entrevistadas podem usar palavras distintas para dizer a mesma coisa, é necessário preparar o material de forma a elevar a chance de que as coocorrências sejam captadas pelo software. Tal atividade consiste em substituir termos de mesmo significado por um único termo ao longo do material a ser analisado. Por exemplo: uma palavra muito utilizada foi bafômetro, mas quando apareciam as palavras etilômetro e equipamento (referindo-se ao bafômetro), elas palavras eram substituídas por bafômetro. Com diversas palavras esse procedimento (que não interfere no conteúdo) foi adotado, como parte da preparação do material textual a ser processado.

$\mathrm{O}$ processamento gera um dendrograma que representa as classes de conteúdos identificadas a partir de coocorrências de palavras. O software realiza uma Classificação Hierárquica Descendente, na qual as palavras vão sendo agrupadas em classes de palavras que coocorrem de forma diferenciada, como já foi dito, classes essas que podem se subdividir em outras classes com a sequência do procedimento, no qual é considerada a frequência com que a palavra aparece e o percentual de ocorrência no grupo de palavras no qual aparece de forma predominante, ou seja, a força de associação da palavra com o contexto (no caso, com a classe) no qual está inserida.
A observação do dendrograma constante da Figura 1 permite verificar que o processamento identificou seis classes estáveis de conjuntos de palavras coocorrentes. Considerando que a linha segmentada presente na parte superior da figura tem função métrica, pois nela cada intervalo corresponde a dez pontos percentuais (deve ser lida da direita para a esquerda), percebe-se que o processamento logo identificou duas grandes classes que praticamente nada compartilham (uma delas se ramifica nas classes 1 e 6; a outra dá origem às classes 2, 3, 4 e 5). Na sequência o processamento dividiu a primeira das duas classes iniciais, considerando que havia elementos diferenciadores que justificavam a proposição de duas novas classes (1 e 6), ainda que elas compartilhassem cerca de $63 \%$ dos seus elementos componentes. Com a segunda das duas classes iniciais os desdobramentos foram maiores. De início o processamento do Alceste encontrou duas novas classes que compartilhavam aproximadamente $35 \%$ do conteúdo, mas, antes de finalizar a análise, o processamento identificou que cada uma delas deveria ser dividida em outras duas, gerando, assim, quatro novas classes, identificadas pelos números 2, 3, 4 e 5 . As classes 2 e 4 compartilham cerca de $63 \%$ dos seus elementos componentes. As classes 3 e 5 compartilham cerca de $69 \%$ dos seus elementos componentes.

Os conteúdos principais de cada uma das seis classes podem ser examinados na Figura 2 , um quadro que reúne as palavras com maior nível de associação com cada uma das classes, conforme evidenciado pelo $\mathrm{x}^{2}$, para cada uma dessas palavras.

A interpretação da Figura 2 envolve busca de vínculos entre as palavras de cada coluna, assim

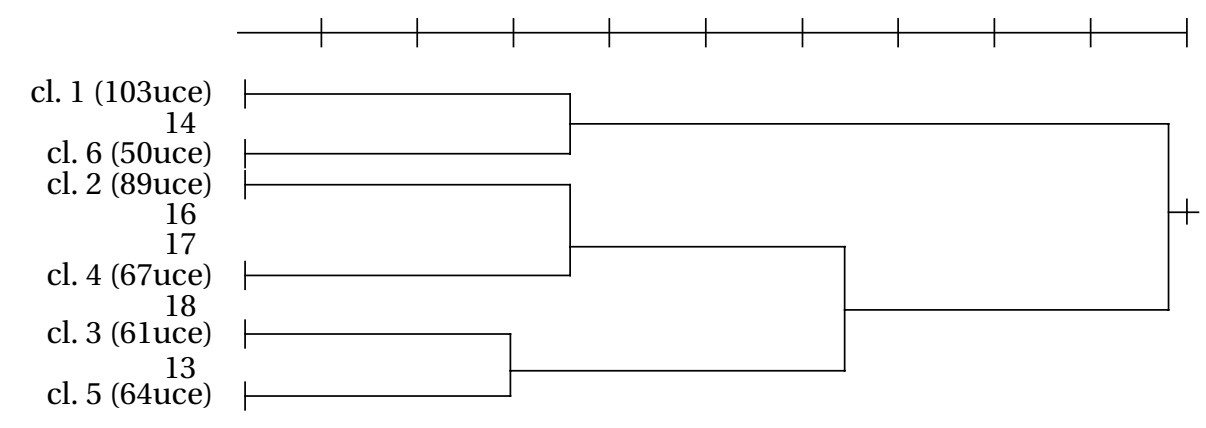

\section{Figura 1}

Dendrograma de classes estáveis de conteúdos. A linha de referência acima da figura indica intervalos de dez pontos percentuais no conjunto de elementos verbais compartilhados nas classes resultantes do processamento. 


\begin{tabular}{|c|c|c|c|c|c|}
\hline Classe 1 & Classe 6 & Classe 2 & Classe 4 & Classe 3 & Classe 5 \\
\hline Carro & Bebida alcoólica & Trânsito & Campanha & $\begin{array}{l}\text { Bafômetro } \\
\text { Soprar }\end{array}$ & Administrativa \\
\hline Odor & Diferença & Efetivo & Compreensão & Obrigatoriedade & Ano \\
\hline Olhos & $\begin{array}{l}\text { Dirigir após } \\
\text { beber }\end{array}$ & Escala Serviço & $\begin{array}{l}\text { Ensino Educação } \\
\text { Trânsito }\end{array}$ & Delegacia & $\begin{array}{l}\text { Carteira } \\
\text { Habilitação }\end{array}$ \\
\hline \multirow[t]{2}{*}{ Pergunta } & Filho & Extra & Educação & Exame & Cassação \\
\hline & Geralmente & $\begin{array}{l}\text { Guarda } \\
\text { municipal }\end{array}$ & Envolvimento & Fato & Ciodes \\
\hline Balada Bar Festa & Homem & Madrugada viva & Escolta & Lei Direito & Detran \\
\hline Bebida alcoólica & Ingerir & Militar & Especificidade & Prova & Flagrar \\
\hline Boa & Jovens & Número & Objetivo & Recusa & Infração \\
\hline Comportamento & Maior & Operação Blitz & Punitivo & & Ocorrência \\
\hline Conseguir & Mulher Marido & Reduzido & Punir & Advogado Juiz & Prazo \\
\hline Cultura Brasil & Namorada & Polícia & & Brecha & Processo \\
\hline Identificação & Responsabilidade & Semana & Agir & Contrariado & Recolher \\
\hline Jovem & & Sexta-feira & Conscientização & Delegado & Reincidente \\
\hline Olhos & Acidente trânsito & Trânsito & Fundamento & Embriaguez & Sanção \\
\hline Simples & Adultos & & Policial & Inútil & Setor \\
\hline Tipo & Carro Veículo & Acidente & Polícia PM & Liberdade & Sistema \\
\hline \multirow[t]{10}{*}{ Vermelho } & Comum & Apoio & Programa & Punição Punido & Suspensão \\
\hline & $\begin{array}{l}\text { Condutor } \\
\text { Embriaguez }\end{array}$ & Aumento & Respeito & Teor & \\
\hline & Perfil & Comando & Treinamento & $\begin{array}{l}\text { Termo } \\
\text { circunstanciado }\end{array}$ & Avaliação \\
\hline & & Delegacia & & Teste & Buscar \\
\hline & & Equipe Tropa & & & Cometer \\
\hline & & Especializado & & & Dado \\
\hline & & GAO & & & Encaminhamento \\
\hline & & Prefeitura & & & Enganar \\
\hline & & Viatura & & & Notificação \\
\hline & & Vitória Vila Velha & & & Primeira \\
\hline
\end{tabular}

\section{Figura 2}

Palavras com maior nível de associação com cada classe. Em cada coluna, a associação das palavras do primeiro grupo é revelada por $\mathrm{x}^{2}$ maior que 20 , e a associação das palavras do segundo grupo (separado do primeiro por uma célula vazia na coluna) é revelada por $\mathrm{x}^{2}$ maior que 12 .

como os aspectos que diferenciam tais palavras daquelas agrupadas em outra coluna. Muitas vezes, é necessário examinar alguns dos segmentos de texto nos quais as palavras aparecem para confirmar o contexto em que elas foram utilizadas, exame esse que é possibilitado pelo próprio software. Isso significa que a Figura 2, vale ressaltar, é apresentada como apoio para a compreensão do texto, mas não pode ser tomada como descrição exaustiva dos dados.

O exame das classes permite constatar que a primeira díade (Classes 1 e 6) reúne um conjunto de informações relativas ao contexto do problema que foi assunto das entrevistas, ou seja, às condições em que ocorre o comportamento de ingestão de bebida alcoólica e às condições em que se faz uso de um bem associado a status, o carro. Considerou-se que essa díade poderia ser nomeada como "Problema".

Sobre a segunda díade (Classes 2 e 4 ), constatou-se que as palavras que a caracterizam remetem ao contexto das ações postas em prática pelas instituições oficiais (Detran e Polícia Militar) com atribuições referentes ao "Problema" que nomeou a díade 
anterior. Considerou-se que essa díade estaria bem nomeada com o uso da palavra "Ação".

A terceira díade encampa um conjunto de referências atinentes às dificuldades de lidar com o "Problema”; aos limites impostos para a "Ação"; aos entraves burocráticos, legais e técnicos para lidar com embriaguez e condução de veículos; e às propostas sobre como resolver algumas dessas dificuldades e como avaliar e aprimorar as ações que já vem sendo adotadas. Na Figura 3 aparece um quadro no qual essa interpretação inicial das díades está posta, com o acréscimo da interpretação dos conteúdos de cada uma das classes isoladamente.

Como se percebe na Figura 3, a Classe 1 foi descrita como "Cultura da naturalização e valorização do beber excessivo". Fica evidente que a escolha dessa definição para a Classe 1 se justifica pelo fato de estarem agrupados termos como odor etílico, olhos vermelhos, bebida alcoólica, balada, festa, cultura jovem, que foram utilizados quase sempre com o sentido proposto na expressão que identifica a classe.

A Classe 6 foi identificada como "Menosprezo do risco da associação entre bebida e direção". Percebese a presença de expressões como dirigir tendo bebido, condutor embriagado, responsabilidade, acidente de trânsito, jovens, adultos, geralmente, homens, comum, filho, namorada, que foram utilizadas em frases que, de diferentes formas, referem-se à pouca preocupação com a prática comum de dirigir após ter ingerido bebida alcoólica, exceto quando se fala dos pais, que parecem se preocupar com os riscos de seus filhos, em geral homens, que são condutores, ou com suas filhas que são namoradas de condutores que ingerem bebida alcoólica antes de dirigir.

A Classe 2 recebeu a denominação "Contexto das Ações de fiscalização”. As palavras componentes dessa classe remetem de forma clara às atividades fiscalizadoras da Polícia Militar, cuja ação principal é a blitz (operação) feita como parte do Programa Madrugada Viva. Entre elas estão: Batalhão de Trânsito, efetivo policial pequeno, escala de serviço, Madrugada Viva, operação, Polícia Militar, delegacia.

A Classe 4 refere-se ao "Contexto das ações educativas", que reúne o conjunto de ações relativas ao trânsito que completam o quadro que também engloba as ações de fiscalização. Podem ser encontrados como termos que o processamento identificou como pertencentes à Classe 4, itens como campanha, compreensão, educativa, educação para o trânsito, conscientização, polícia, programa, respeito, treinamento.

A Classe 3 foi interpretada como dizendo respeito aos "Aspectos Legais e operacionais em torno da verificação da embriaguez". Pode ser verificado que tal classe é composta por termos como: bafômetro, exame, recusa de soprar o bafômetro,

\begin{tabular}{|c|c|c|c|}
\hline $\begin{array}{l}\frac{\pi}{0} \\
\frac{0}{0} \\
0 \\
0 \\
0 \\
0\end{array}$ & $\begin{array}{l}\text { Classes } \\
1 \text { e } 6\end{array}$ & $\begin{array}{l}\text { Consumo de bebida alcoólica bar, balada, } \\
\text { festa, jovens, ingestão abusiva } \\
\text { Carro, direção, bebida (direito, privacidade, } \\
\text { prioridade) } \\
\text { Cultura brasileira e status atribuído ao carro } \\
\text { e ao consumo de bebida alcoólica }\end{array}$ & $\begin{array}{l}\text { Classe } 1 \text { Cultura da naturalização e } \\
\text { valorização do beber excessivo } \\
\text { Classe } 6 \text { Menosprezo do risco da associação } \\
\text { entre bebida e direção }\end{array}$ \\
\hline 恚 & $\begin{array}{l}\text { Classes } \\
2 \text { e } 4\end{array}$ & $\begin{array}{l}\text { Programas fiscalizadores e educativos } \\
\text { Ações práticas - operações fiscalizadoras, } \\
\text { campanhas educativas } \\
\text { Equipes - insuficiência } \\
\text { Dificuldades operacionais }\end{array}$ & $\begin{array}{l}\text { Classe } 2 \text { Contexto das ações de fiscalização } \\
\text { Classe } 4 \text { Contexto das ações educativas }\end{array}$ \\
\hline 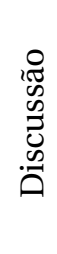 & $\begin{array}{l}\text { Classes } \\
3 \text { e } 5\end{array}$ & $\begin{array}{l}\text { Aspectos legais - dificuldades/brechas na Lei } \\
\text { Seca } \\
\text { Críticas e sugestões à lei } \\
\text { Punições administrativas } \\
\text { Conflitos Institucionais } \\
\text { Detran e Punição }\end{array}$ & $\begin{array}{l}\text { Classe } 3 \text { Aspectos legais e operacionais em } \\
\text { torno da verificação da embriaguez } \\
\text { Classe } 5 \text { Aspectos legais e operacionais } \\
\text { relativos à punição do condutor }\end{array}$ \\
\hline
\end{tabular}

Figura 3

Quadro-resumo da interpretação do conteúdo das classes. 
necessidade de que seja obrigatório fazê-lo, delegacia, lei seca, brecha na lei, advogado, juiz, embriaguez, inútil, teor alcoólico, termo circunstanciado. Essa classe diz respeito à discussão (e ao inconformismo) dos policiais com relação ao fato de não ser obrigatório submeter-se ao exame de verificação de teor alcoólico por meio do bafômetro; ao reconhecimento por parte desses policiais de que em tal quadro o seu trabalho pode ser inútil; e às dificuldades com delegados, advogados e juízes para levar adiante a punição frente à constatação de irregularidades. A sugestão dos fiscalizadores é a de que o exame de teor alcoólico seja obrigatório e que as punições estejam estabelecidas de forma clara e sejam aplicadas pelos Departamentos de Trânsito.

A Classe 3 está muito relacionada com a Classe 5, que trata de assunto similar por outra vertente, com maior ênfase não na constatação da embriaguez, mas nas dificuldades gerais que decorrem da legislação. A Classe 5 foi nomeada como "Aspectos legais e operacionais relativos à punição do condutor", por razões que ficam evidentes quando são considerados os termos agrupados na classe: Detran, suspensão e cassação de carteira, flagrante, infração, notificação, processo, prazo, reincidência, sistema judiciário. O que está em jogo é a discussão das dificuldades operacionais, institucionais e legais para se chegar à punição de infratores. Os policiais entrevistados destacaram as dificuldades do Detran em chegar até mesmo à punição mais óbvia que seria a cassação de habilitações, mesmo diante de flagrantes com comprovações da embriaguez e, em alguns casos, com acidentes, além das dificuldades de identificar reincidentes. As dificuldades que resultam da intervenção de advogados, a morosidade dos processos no sistema judiciário, os prazos longos demais para se chegar a qualquer definição processual, as dificuldades de articulação entre Detran e outras instituições.

Ainda que não se trate de uma perspectiva crítica articulada de forma sofisticada com aspectos da organização social brasileira e da natureza do projeto de mobilidade urbana que é privilegiado nas cidades do país, fica evidente que os policiais militares que atuam na fiscalização de motoristas percebem inúmeras dificuldades legais e sociais que funcionam como obstáculos permanentes no caminho de qualquer solução realmente eficaz para os problemas com os quais têm que lidar. Nobre
(2010) e Lancman, Sznelwar, Uchida e Tuacek (2007) destacaram a dualidade de sentimentos dos usuários que os policiais percebem em relação ao seu trabalho, no sentido de que as ações que visam proteger o motorista são bem avaliadas, enquanto as que visam corrigí-los são mal recebidas pelos condutores.

Essas percepções foram expressas por um agente essencial no enfrentamento de um problema que exige fiscalização com abordagem pública em vias públicas: os policiais de trânsito. Trata-se, portanto, de um tipo de material importante a ser considerado pelos formuladores de políticas em relação à mobilidade humana, com foco privilegiado na questão de expressivo impacto social que diz respeito à prática de dirigir sob efeito de bebida alcoólica (Bacchieri, \& Barros, 2011). Esse material também é importante para atualizar conhecimento sobre os procedimentos de fiscalização e seu planejamento por órgãos superiores da polícia e da justiça, mas também sugere cuidados importantes em relação à formação dos policiais militares.

Um dos aspectos que ficou ressaltado no relato dos policiais é a convicção de que ações de fiscalização e de punição devem ser separadas. Eles expressaram nas entrevistas certo desconforto de verem misturadas no mesmo espaço de atuação policial a ação educativa conduzida por equipe técnica não policial. Argumentaram pela impropriedade de práticas educativas frente a indivíduos alcoolizados e mostraram preocupação com a proteção de quem está na cena com objetivos educativos, uma vez que as operações de fiscalização envolvem riscos de surpreender atividades criminosas e reação de motoristas armados. A visão, esclarecida nas entrevistas, de que a atividade policial é algo apartado de práticas educativas é discutível e, por isso, tema merecedor de reflexão por parte de quem planeja a formação de policiais.

Os entrevistados revelaram, com satisfação, sua percepção de que o programa de fiscalização é visto de forma positiva por boa parte da população. Trata-se de ponto importante por representar, em certa medida, exceção no trabalho da Polícia Militar (PM), muitas vezes apresentado pelos meios de comunicação como truculento, corporativo e ineficaz. É razoável pensar que há interesse especial em conservar essa atividade cujo impacto social é reconhecido. Talvez por isso tenha sido manifestada preocupação com o risco do trabalho da PM 
ser visto como perda de tempo pela falta de amparo legal para exigir que o teste do etilômetro seja realizado, pelas dificuldades de ver algum infrator punido de fato, e pela tolerância com os mecanismos de burla das operações de fiscalização. Tais dificuldades são acirradas pelo reduzido quadro de policiais do Batalhão de Trânsito, na concepção dos entrevistados. Os policiais mencionaram também a indisponibilidade de mecanismos que permitam aferir se o infrator é reincidente, informação que pode ser muito útil. Há risco potencial de desestímulo com o trabalho.

Outro ponto de dificuldade salientado pelos policiais participantes do estudo é a natureza da interação com a Polícia Civil. Uma das questões diz respeito ao fato de que um indivíduo flagrado alcoolizado precisa ser levado à Delegacia de Delitos de Trânsito (Polícia Civil), o que exige deslocamento de policiais militares que devem fazer o acompanhamento e desfalca o grupo já pequeno que realiza as operações. A delegacia citada, por seu lado, tem outras atribuições também importantes e não pode estar à disposição das operações de fiscalização com a agilidade de atendimento necessária.

Ao se referirem sobre o que consideram cultura de valorização do beber excessivo e menosprezo do risco da associação entre bebida e direção os policiais evidenciaram certas concepções compartilhadas. Uma delas é que o problema tem grande dimensão, o que é concordante com informações disponíveis na literatura. O I Levantamento Nacional Domiciliar sobre Padrões de Consumo de Álcool (2007), realizado nos anos de 2005 e 2006, mostrou que 34\% dos participantes relatam experiências de beber e dirigir. $\mathrm{O}$ estudo mostra ainda que dirigir alcoolizado no Brasil é muito comum, seja por se tratar de uma sociedade motorizada, seja pela relação existente entre o beber e o lazer, relação culturalmente consolidada no país. Os autores sugerem que a associação entre veículo e bebida alcoólica parece ser inevitável em muitos casos, principalmente em situações de "bares e baladas" (Laranjeira, Pinsky, Zaleski, \& Caetano, 2007), o que também pode ser constatado em outros estudos que investigaram acidentes de trânsito associados ao consumo abusivo de bebidas alcoólicas (Bacchieri, Barros, Santos, \& Gigante, 2010; De Boni, Leukefeld, \& Pechansky, 2008; Salgado et al., 2012).

Outra concepção está evidenciada na concordância entre os policiais quanto ao fato dos jovens serem os alvos preferenciais privilegiados das operações de fiscalização, tendo surgido, inclusive, afirmações de que para os adultos que já dirigem há muito tempo pouco há a fazer, porque eles não mudarão suas práticas. Mesmo considerando que adultos também podem aprender e se transformar, o que poderia ser considerado na formação dos policiais, a literatura mostra exemplos de que os jovens estão mais presentes nos acidentes de trânsito, e uma das razões é a bebida alcoólica. Marín-León e Vizzoto (2003), por exemplo, em estudo realizado em Campinas com 2.116 estudantes universitários, constataram que os rapazes com mais de 20 anos e com melhor condição socioeconômica têm chances mais elevadas de sofrerem acidentes de trânsito e, mesmo para aqueles sem antecedentes de acidentes de trânsito, foi constatada alta frequência de comportamentos inadequados, como dirigir em velocidade excessiva, desrespeitar sinais de trânsito e ingerir bebida alcoólica e a seguir dirigir veículo. Em outro exemplo, Dotta-Pannichi (2005), em estudo com 400 adolescentes e jovens adultos, verificou associação entre pais negligentes ou muito permissivos e altos índices de exposição a riscos na condução de automóveis por parte de seus filhos, constatando também que atitudes permissivas de pais e parentes frente ao uso de álcool por adolescentes e jovens estão associadas a maior incidência de comportamentos de risco ao volante.

Os policiais também concordaram quanto à percepção de que parte importante dos recursos publicitários que sustentam os meios de comunicação é proveniente de anunciantes cujos produtos estão relacionados ao problema com o qual eles têm que lidar, com o que anunciantes e meios de comunicação estão implicados na prática de beber e dirigir. Grande volume da publicidade à qual a população está exposta na televisão diz respeito, precisamente, a automóveis e bebidas alcoólicas, além da telefonia celular (de passagem, registra-se que o uso do celular durante a direção automotiva também está associado a acidentes). A publicidade tanto de automóveis como de bebidas salienta o que tais produtos podem significar em termos de status, diferenciação social, conquistas, amizades e diversão. Não há recomendação publicitária de vantagens e ganhos com a associação de bebida e carro, mas também não há qualquer preocupação com a sinalização de providências mínimas de 
cautela e de estratégias apropriadas para lidar com o risco de tal associação, exceção feita às vinhetas cuja apresentação é exigida pela legislação no caso da bebida alcoólica. Recorda-se aqui que, de acordo com Melcop (2004), o símbolo de conquista social que a propriedade do automóvel representa se estende ao lazer (e ao beber, certamente) em ambientes nos quais os interlocutores também são proprietários de veículos.

Acredita-se que tornar conhecidas as concepções de policiais sobre vários aspectos das operações de fiscalização de motoristas com vistas a verificar se estão sob efeito de bebida alcoólica, considerando que todos os participantes do estudo atuam diretamente em tais operações, é proporcionar subsídios importantes para órgãos policiais, legislativos e judiciários que planejam e avaliam atividades dessa natureza. Não

\section{Referências}

Associação Brasileira de Educação de Trânsito - ABETRAN. (2014). Agora são 9 pessoas condenadas e presas por crime de trânsito no Brasil!! Recuperado de http://abetran.org.br/index.php?option $=$ com_content $\&$ task $=v i e w \& i d=27720 \&$ Itemid $=2$

Associação Nacional de Transportes Públicos - ANTP. (1997). Transporte humano: cidades com qualidade de vida. São Paulo, SP: ANTP.

Associação Nacional dos Fabricantes de Veículos Automotores do Brasil - ANFAVEA. (2012). Anuário da indústria automotiva brasileira. Recuperado de http://www.anfavea.com.br/anuario.html

Barczak, R., \& Duarte, F. (2012). Impactos ambientais da mobilidade urbana: cinco categorias de medidas mitigadoras. Revista Brasileira de Gestão Urbana, 4(1), p. 13-32. Recuperado de http://www2. pucpr.br/reol/pb/index.php/urbe?ddl $=6027 \& d-$ d99=view\&dd98=pb

Bacchieri, G., Barros, A. J., Santos, J. V., \& Gigante, D. P. (2010). Cycling to work in Brazil: users profile, risk behaviors, and traffic accident occurrence. Accident Analysis \& Prevention, 42(4), 1025-1030. doi:10.1016/j.aap.2009.12.009

Bacchieri, G., \& Barros, A. J. D. (2011). Acidentes de trânsito no Brasil de 1998 a 2010: muitas mudanças e poucos resultados. Revista de Saúde Pública, 45(5), 949-63. doi:10.1590/S0034-89102011005000069

Bonduki, N. (2011). O modelo de desenvolvimento urbano de São Paulo precisa ser re- é simples compreender as dificuldades que são enfrentadas para lidar com tal questão uma vez que, como já se viu ao longo do texto, trata-se de assunto sobre o qual não há discordância essencial, ou seja, não há defensores da ideia de que a associação bebida alcoólica e direção automotiva seja prática defensável e com baixo potencial de risco, embora sempre se encontre motoristas que argumentarão, com base em sua experiência pessoal, que esse risco pode ser pouco expressivo em algumas circunstâncias. Também não há discordância fundamental em relação ao fato do risco não ficar limitado ao próprio motorista, mas se estender a qualquer outra pessoa que esteja no veículo, em outros veículos, ou em qualquer local alcançável por um veículo desgovernado. Conhecer a maior diversidade possível de informações sobre o assunto é passo essencial para com ele poder lidar de forma eficiente.

vertido. Estudos Avançados, 25(71), 23-36. doi:10.1590/S0103-40142011000100003

Brasil. (2008), Ministério das Cidades, Conselho Nacional de Trânsito. Código de trânsito brasileiro e legislação complementar em vigor. Brasília, DF: Denatran.

Brismar, B., \& Bergman, B. (1998). The significance of alcohol for violence and accidents. Alcoholism, Clinical and Experimental Research, 22(suppl s7), 299S-306S. doi:10.1111/j.1530-0277.1998.tb04382.x

Campos, V. R., Salgado, R., Rocha, M. C., Duailibi, S., \& Laranjeira, R. (2012). Beber e dirigir: características de condutores com bafômetro positivo. Revista de Psiquiatria Clínica, 39(5), 166-171. doi:10.1590/ S0101-60832012000500004

Creswell, J. W. (2007). Projeto de pesquisa: métodos qualitativo, quantitativo e misto. Porto Alegre, RS: ArtMed.

DaMatta, R., Vasconcellos, J. G., \& Pandolfi, R. (2010). Fé em Deus e pé na tábua. Ou como e porque o trânsito enlouquece no Brasil. Rio de Janeiro, RJ: Rocco.

Damiani, A. L. (2006). Cidades médias e pequenas no processo de globalização: apontamentos bibliográficos. In A. I. G. Lemos, M. Arroyo, M. L. Silveira (Orgs.), América Latina: cidade, campo e turismo (135-147). São Paulo, SP: Consejo Latinoamericano de Ciencias Sociales.

De Boni, R., Leukefeld, C., \& Pechansky, F. (2008). Alcoolemia de jovens e lei contra o consumo de 
álcool. Revista de Saúde Pública, 42(6), 1101-4. doi:10.1590/S0034-89102008005000054

Dotta-Panichi, R. M. (2005). O jovem e o comportamento no trânsito: uma análise dos indicadores de risco e proteção no contexto familiar (Dissertação de mestrado). Porto Alegre, RS: Universidade Católica do Rio Grande do Sul.

Dupuy, G. (1995). Les territoires de l'automobile. Paris: Antropos.

Gaskell, G., \& Bauer, M. W. (2002). Pesquisa qualitativa com texto, imagem e som: um manual prático. Petrópolis, RJ: Vozes.

Jato, R. (2007). Escolhas associadas ao automóvel (Dissertação de mestrado). São Caetano do Sul, SP: Universidade Municipal de São Caetano do Sul.

Lancman, S., Sznelwar, L. I., Uchida, S. \& Tuacek, T. A. (2007). O trabalho na rua e a exposição à violência no trabalho: um estudo com agentes de trânsito. Interface - Comunicação, Saúde, Educação, 11(21), 79-92. doi:10.1590/S1414-32832007000100008

Laranjeira, R., Pinsky, I., Zaleski, M., \& Caetano, R. (2007). I Levantamento Nacional sobre os padrões de consumo de álcool na população brasileira. Brasília, DF: Secretaria Nacional Antidrogas.

Leyton, V., Greve, J. M. D. A., Carvalho, D. G., \& Muñoz, D. R. (2005). Perfil epidemiológico das vítimas fatais por acidente de trânsito e a relação com o uso do álcool. Saúde, Ética \& Justiça, 10(1/2), 12-8.

Lorentz, I. (2008). "Só podia ser mulher": as relações de gênero no trânsito (Dissertação de mestrado). Ijuí, RS: Universidade do Noroeste do Estado do Rio Grande do Sul.

Ludd, N. (2005). Apocalipse motorizado: a tirania do automóvel em um planeta poluído. São Paulo, SP: Conrad.

Marín-Léon, L., \& Vizzoto, M. M. (2003). Comportamentos no trânsito: um estudo epidemiológico com estudantes universitários. Cadernos de Saúde Pública, 19(2), 515-523. doi:10.1590/S0102-311X2003000200018

Melcop, A. G. T. (2004). Vamos parar por aqui? Os desafios da abordagem de redução de danos nas violências no trânsito. In Brasil. Ministério da Saúde. Álcool e redução de danos: uma abordagem inovadora para países em transição (85-102). Brasília, DF: o autor.

Moura, E. C., Malta, D. C., Morais-Neto, O. L., Penna, G. O., \& Temporão, J. G. (2009). Direção de veículos motorizados após consumo abusivo de bebidas alcoólicas, Brasil, 2006 a
2009. Revista de Saúde Pública, 43(5), 891-894. doi:10.1590/S0034-89102009005000062

Moura, R., Castello Branco, M. L. G., \& Firkowski, O. L. C. F. (2005). Movimento pendular e perspectivas de pesquisas em aglomerados urbanos. São Paulo Perspectiva, 19(4), 121-133. doi:10.1590/S0102-88392005000400008

Nascimento, A. S. (2008). Programa Madrugada Viva: análise da formulação e implementação de política pública de redução da violência e acidentes no trânsito causados pelo uso indevido do álcool no Estado do Espírito Santo (Dissertação de mestrado). Vitória, ES: Universidade Federal do Espírito Santo.

Nobre, M. P. P. (2010). Conflitos no trânsito: Intervenções ou moderações psicopedagógicas podem ajudar no relacionamento dos agentes de operação e fiscalização de trânsito com os motoristas? Construção Psicopedagógica, 18(16), 94-111. Recuperado de: http://pepsic.bvsalud.org/scielo.php?script=sci_arttext\&pid=S1415-69542010000100009

Oliveira, L. G., Yonamine, M., Andreucceti, G., Ponce, J. C., \& Leyton, V. (2012). Alcohol and other drug use by Brazilian truck drivers: a cause for concern? Revista Brasileira de Psiquiatria, 34(1), 116-117. doi:10.1590/S1516-44462012000100020

Pechansky, F; Duarte, P. C. A. V., \& De Boni, R. B. (2010). Uso de bebida alcoólica e outras drogas nas rodovias brasileiras. Porto Alegre, RS: Secretaria Nacional de Políticas sobre Drogas.

Petridou, E., \& Moustaki, M. (2000). Human factors in the causation of road traffic crashes. European Journal of Epidemiology, 16(9), 819-826. doi:10.1023/A:1007649804201

Reinert, M. (1990). Alceste, une méthodologie d'analyse des donées textuelles et une application: Aurélia de G. de Nerval. Bulletin de Méthodologie Sociologique, 28, 24-54.

Rolnik, R., \& Klintowitz, D. (2011). (I)Mobilidade na cidade de São Paulo. Estudos Avançados. 25(71), 89108. doi:10.1590/S0103-40142011000100007

Salgado, R. S., Campos, V. R., Duailibi, S., \& Laranjeira, R. R.(2012). O impacto da "Lei Seca" sobre o beber e dirigir em Belo Horizonte/MG.Ciência\&SaúdeColetiva,17(4),971-976. doi:10.1590/S1413-81232012000400019

Vasconcellos, E. A. (2005). A cidade, o transporte e o trânsito. São Paulo, SP: Prolivros.

Vasconcellos, E. A. (1998). O que é trânsito? São Paulo, SP: Brasilense. 


\section{Andrea dos Santos Nascimento}

Doutora pela Universidade Federal do Espírito Santo,

Vitória-ES. Brasil.

E-mail: andreanas@gmail.com

Paulo Rogério Meira Menandro

Docente da Universidade Federal do Espírito Santo, Vitória-ES. Brasil.

E-mail: paulomenandro@uol.com.br

Endereço para envio de correspondência:

Consultório Particular. Alameda Casa Branca, 851.

Jardim Paulista. CEP: 29055-060. Vitória - ES. Brasil.
Recebido: $18 / 05 / 2014$

Reformulado: 23/11/2015

Aprovado: 03/04/2016

Received: 05/18/2014

Reformulated: 11/23/2015

Approved: 04/03/2016

Recibido: 18/05/2014

Reformulado: 23/11/2015

Aceptado: 03/04/2016

Como citar: Nascimento, A. S., \& Menandro, P. R. M. (2016). Bebida alcoólica e direção automotiva: relatos de policiais militares obre a “Lei Seca”. Psicologia: Ciência e Profissão, 36(2): 411-425. doi:10.1590/1982-3703000672014

How to cite: Nascimento, A. S., \& Menandro, P. R. M. (2016). Alcoholic beverage and driving: reports of military policy officers on “Lei Seca”. Psicologia: Ciência e Profissão, 36(2): 411-425. doi:10.1590/1982-3703000672014

Cómo citar: Nascimento, A. S., \& Menandro, P. R. M. (2016). Bebida alcohólica y conducción automovilística. Relato de policías militares sobre la “ley seca”. Psicologia: Ciência e Profissão, 36(2): 411-425. doi:10.1590/1982-3703000672014| 